\title{
Analysis of Regional Economic Structure Upgrading Based on Environmental Governance-Taking Pearl River Delta as an Example
}

\author{
Xia Li \\ Economic College, Jinan University, Guangzhou, China \\ Email: lixia77761@163.com \\ Received 17 December 2015; accepted 15 January 2016; published 18 January 2016 \\ Copyright (C) 2016 by author and Scientific Research Publishing Inc. \\ This work is licensed under the Creative Commons Attribution International License (CC BY). \\ http://creativecommons.org/licenses/by/4.0/

(c) (i) Open Access

\begin{abstract}
The paper is a foundation with multi-objective programming model, uses panel data which are from 2005 to 2013 from the Pearl River Delta region, and constructs multi objective optimization model of regional economic structure based on Environmental Management so as to get the plan which can reduce the environmental pollution and optimize the industrial structure, property right structure, urban and rural structure, open structure, technical structure and environmental pollution in the Pearl River Delta region, and put forward policy for the construction of environment friendly area in the Pearl River Delta.
\end{abstract}

\section{Keywords}

Pearl River Delta, Area, Economic Structure, Environmental Management, Multi-Objective Programming Mode

\section{Introduction}

The Pearl River Delta located in the south of Guangdong Province, adjacent to Hong Kong and Macao, opposite Asia area, is regarded as the south gate of China and contains nine prefecture-level cities (Guangzhou, Shenzhen, Foshan, Dongguan, Zhuhai, Zhongshan, Zhaoqing, Jiangmen, Huizhou). As the first area of China's reform and opening up the world and in awe of what, the Pearl River Delta has accomplished. According to the statistical data of Guangdong Province in 2014, Pearl River Delta accounted for less than 1\% of national land area to feed the $4.2 \%$ of the country's population, created 9 percent of the China's GDP, reached the economy development 
level in medium-level developed countries. Pearl River Delta is the world's advanced manufacturing base, the national scientific and technological innovation and technology research and development base, and the important engine of economic development [1]. Pearl River Delta with a solid foundation, a strong development potential, our country population densest, economy most develop, most innovation ability, is one of the most comprehensive strength regions. But the rapid development of the Pearl River Delta economy is built on the basis of industrialization. With the rapid development of industrialization, environmental pollution will be inevitable [2]. The Pearl River Delta in the rapid development of industrialization in the past ten years, due to the large amount of pollutant emissions, less environmental governance, environmental pollution is becoming more and more serious. Therefore, it is of great significance to study the effective control of the Pearl River Delta regional pollution sources, which is of great significance to the sustainable, healthy and stable development of the Pearl River Delta.

\section{Literature Review on Economic Structure Optimization and Environmental Management in the Pearl River Delta}

Scholars have done a lot of research on the relationship between economic structure optimization and environmental governance. Grossman and Krueger is divided factors effect of the adjustment of industrial structure on environmental pollution reduction into Economic scale effect, structure effect and technology effect [3]. Bruvoll and Medin from the economic scale and structure changes, technology and other factors explained the real cause of the formation of the environment Cruz Nez curve according to the economic scale and structure changes, technology and other factors. Research shows that the economic scale of the growth is the main cause of the deterioration of the environmentt [4]. Stern found that optimizing the structure of input and output has a significant effect on reducing environmental pollution by analyzing the causes of the formation of the 64 national environmental Kuznets curve [5]. Shandra believe that industrial restructuring will lead to increased water pollution [6]. Jalil and Feridum pointed out that a loss of the proportion of the industry and the development of the financial industry can reduce carbon emissions [7]. Liu Xisong and Li Guo explored the relationship between industrial structure and environmental governance. The results showed that the adjustment of industrial structure on improving the role of resources and environment cannot be ignored [8]. Peng Shuijun and Bao Qun analyzed the relationship between economic growth and environmental pollution, showed that the industrial dust and a per capita GDP presents $\mathrm{N}$ type curve correlation, so2 and a per capita GDP presents $\mathrm{U}$ type curve correlation [9]. Su Yongzheng explored the relationship between energy saving and emission reduction, optimization of industrial structure and transformation of economic development mode, believed that energy-saving and emission reduction is the key point of industrial structure optimization and the transformation of economic development mode, and that industrial structure optimization is the main way of the transformation of economic development mode [10]. Zhang Pingdan explored the relationship between economic structure and pollutant emissions in China. The results showed that with the improvement of economic structure, the pollutant discharge is gradually declining, and the economic structure and pollutant emissions are negative correlation, which means the improvement and optimization of the economic structure is helpful to the environmental governance [11]. Liu Chun analyzed the economic scale, industrial structure and technical which influence environmental problems with empirical model of industrial structure and environmental pollution, and suggested that optimizing industrial structure, increasing investment in environmental governance and improving the treatment technology of environmental pollution [12]. Yuan Yijun and Xie Ronghui believed that environmental governance can be used as a new driving force for industrial structure adjustment, through the analysis of the data of 30 provinces in China [13].

At present, many scholars have carried out a lot of research on the relationship between environmental governance and economic structure upgrading. However, the study of combination of environmental governance and region economy structural adjustment is very little. Along with the regional economic integration much deeper, scholars will pay more attention to regional economic structure and environmental governance in the future.

\section{The Urgency of Regional Economic Structure Optimization}

There are 74 cities Implement new air quality standards in 2013. Annual monitoring results showed that the Pearl River Delta is considered to be relatively heavy air pollution area. The problem of environmental pollution 
in the Pearl River Delta is mainly in the following two aspects:

One is that the water environment pollution. The quality of water environment is one of the most serious problems in the Pearl River Delta. By the end of 2014, more than 30\% river water quality were worse than grade V in over 100 major rivers in the Pearl River Delta, and About $90 \%$ of the water quality worse than grade V in over 10 thousand rivers. Water environment pollution control is very urgent.

The other is that the air pollution. The air quality of the Pearl River Delta is so worrying. Air pollutant emissions are large. The primary pollutant in the Pearl River Delta is the particulate matter which accounted for $46 \%$ of pollutants. Then the ozone is accounted for $27 \%$ and nitrogen dioxide is accounted for $18 \%$ [14]. According to the Ministry of environmental protection website news, pollutant emissions in the Pearl River delta is China's five times.

\section{Construction of Multi Objective Programming Model of Regional Economic Structure}

\subsection{Decision Variable}

Pearl River Delta contains nine cities. The factors that affect the optimization of regional economic structure are industrial structure, property right structure, urban and rural structure, technical structure, consumption structure and open structure. Set $X_{i j}(i=1,2, \cdots, 9 ; j=1,2, \cdots, 6)$ to the $j$ factor of the $i$ city. $i$ refers to the cities, 1 for Guangzhou, 2 for Shenzhen, 3 for Zhuhai, 4 for Foshan, 5 for Huizhou, 6 for Dongguan, 7 for Zhongshan, 8 for Jiangmen, and 9 for Zhaoqing. $j$ refers to the economic structure, 1 is the industrial structure, 2 is the property right structure, $j=3$ is the urban and rural structure, 4 is the technical structure, 5 is the open structure, and 6 is the consumption structure.

Industrial structure is equal to the total industrial output value accounted for GDP. The structure of property rights is equal to the urban workers of state-owned enterprises accounted for of workers in Urban. Urban and rural structure is equal to the proportion of urban population in the resident population. Technical structure is equal to the industrial enterprise new product output value accounted for GDP. Open structure is equal to the exports accounted for total volume of imports and exports. Consumption structure is equal to the final consumption expenditure accounted for GDP.

\subsection{Objective Function}

Goal of environmental optimization cannot be achieved at the expense of the economy, but to promote the environment and the regional economy to common development. Therefore, environmental improvement requires that the pollutant emission is as little as possible and economic output is as much as possible. Therefore, this paper constructs the dual objective function of environmental pollution emissions and regional economic output.

$$
\begin{gathered}
\text { Min } \ln E_{k}=\sum_{i=1}^{9} \sum_{j=1}^{6} c_{j} x_{i j} ; \quad(k=1,2) \\
\text { Max } \ln Y=\sum_{i=1}^{9} \sum_{j=1}^{6} a_{j} x_{i j}
\end{gathered}
$$

Equation (1) is the objective function of pollutant emissions. $E_{1}$ is the industrial wastewater emissions (ton) of every 10 thousand yuan GDP. $E_{2}$ is the industrial sulfur dioxide emissions (ton) of every 100 million yuan GDP, $C_{j}$ is the coefficient of pollutant emissions factor $j, c_{j}$ 's calculation method is derived from the study of the relationship between industrial wastewater (sulfur dioxide) emissions and economic structure in the Pearl River Delta region.

Equation (2) is the target function for regional economic output. $Y$ is GDP. $a_{j}$ is the coefficient of economic output factor j. $a_{j}$ 's calculation method is derived from the study of the relationship between GDP and economic structure in the Pearl River Delta region.

\subsection{Constraint Condition}

1) Pollutant emissions constraint

The figures for 2013 are used as a baseline for the study. The cutting rate of every 10 thousand yuan GDP in- 
dustrial wastewater emissions and every 100 million yuan GDP industrial sulfur dioxide emissions increase at least $5 \%$. Under these conditions, increase regional economic output as much as possible.

2) Economic output target constraint

The figures for 2013 are used as a baseline for the study. Regional economic output must be greater than that of 2013. And the output growth rate must be less than or equal to $25 \%$.

3) Influence factors constraint

The figures for 2013 are used as a baseline for the study. The fluctuations of industrial structure, property right structure, urban and rural structure, technical structure, open structure, and consumption structure are between $-5 \%$ and 5\%. Table 1 is the values of the economic structure in 2013.

\section{Solving and Analysis of Regional Economic Structure Optimization Multi Objective Programming Model}

\subsection{Solution of Multi Objective Programming Model}

In order to use the LINGO software to solve the multi object programming problem. Generally, a multi objective programming problem is converted to a single objective programming problem. Therefore, sum up and convert the decision variables, objective function and constraint conditions, and use specific data. So as to establish the model as follows:

$$
\begin{gathered}
\operatorname{Min} \quad z=p_{1}\left(d_{1}^{+}+d_{2}^{+}\right)+p_{2} d_{3}^{-} \\
\text {S.T. } \sum_{i=1}^{9} 0.043058 x_{i 1}+0.005376 x_{i 2}-0.021533 x_{i 3}-0.043040 x_{i 4}+0.056150 x_{i 5}-0.001835 x_{i 6}+d_{1}^{-}-d_{1}^{+}=F_{1}^{*} ; \\
\sum_{i=1}^{9} 0.045291 x_{i 1}+0.00991 x_{i 2}+0.07251 x_{i 3}-0.012796 x_{i 4}-0.122470 x_{i 5}+0.043924 x_{i 6}+d_{2}^{-}-d_{2}^{+}=F_{2}^{*} ; \\
\sum_{i=1}^{9}-0.033361 x_{i 1}-0.003459 x_{i 2}+0.018545 x_{i 3}+0.021117 x_{4}+0.118386 x_{i 5}+0.044262 x_{i 6}+d_{3}^{-}-d_{3}^{+}=F_{3}^{*} ; \\
0 \leq F_{1}^{*} \leq 20.73794 \quad(\text { industrial wastewater emissions constraints }) ; \\
0 \leq F_{2}^{*} \leq 18.97877 \quad(\text { industrial sulfur dioxide emissions constraints }) ; \\
89.55826 \leq F_{3}^{*} \leq 111.9478 \quad(\text { regional economic output constraints }) ; \\
x_{i j(2013)}-5 \leq x_{i j} \leq x_{i j(2013)}+5 \quad(i=1,2, \cdots, 9 ; j=1,2, \cdots, 6) ;(\text { structural optimization factor constraints }) ;
\end{gathered}
$$

Table 1. The values of the economic structure in 2013.

\begin{tabular}{ccccccc}
\hline \multicolumn{1}{c}{$x_{i j}$} & $\begin{array}{c}\text { Industrial } \\
\text { structure } \\
(j=1)\end{array}$ & $\begin{array}{c}\text { Property right } \\
\text { structure }(j=2)\end{array}$ & $\begin{array}{c}\text { Urban and rural } \\
\text { structure }(j=3)\end{array}$ & $\begin{array}{c}\text { Technical } \\
\text { structure } \\
(j=4)\end{array}$ & $\begin{array}{c}\text { Open } \\
\text { structure } \\
(j=5)\end{array}$ & $\begin{array}{c}\text { Consumption } \\
\text { structure }(j=6)\end{array}$ \\
\hline Guangzhou $(i=1)$ & 30.8 & 22.79 & 85.27 & 17.16 & 52.82 & 48.80 \\
Shenzhen $(i=2)$ & 40.6 & 10.90 & 100 & 45.42 & 56.88 & 42.47 \\
Zhuhai $(i=3)$ & 46.7 & 13.90 & 87.85 & 52.29 & 48.96 & 40.71 \\
Foshan $(i=4)$ & 59.9 & 11.71 & 94.88 & 31.09 & 66.50 & 41.03 \\
Huizhou $(i=5)$ & 54.7 & 21.21 & 66.00 & 81.93 & 58.06 & 48.67 \\
Donggua $(i=6)$ & 44.4 & 6.33 & 88.75 & 21.39 & 59.36 & 54.65 \\
Zhongshan $(i=7)$ & 53.2 & 8.65 & 88.00 & 28.53 & 74.32 & 43.20 \\
Jiangmen $(i=8)$ & 48.2 & 22.7 & 64.10 & 19.45 & 70.94 & 48.82 \\
Zhaoqing $(i=9)$ & 44.4 & 36.31 & 43.82 & 12.12 & 68.77 & 48.38 \\
\hline
\end{tabular}

Remarks: The calculating of data grew out of the relevant data of Guangdong statistical yearbook in 2014. 


$$
d_{k}^{-}, d_{k}^{+} \geq 0 \quad(k=1,2,3)
$$

In the above model, $F_{1}^{*}$ represents the constraint value of the logarithm of industrial waste water emissions of every 10 thousand yuan GDP, $F_{2}^{*}$ represents the constraint value of the logarithm of industrial sulfur dioxide emissions of every 100 yuan million GDP, $F_{3}^{*}$ represents the constraint value of the logarithm of total output of region. $x_{i j}$ represents the value of city $i$ of factor $j . x_{i j(2013)}$ represents the value of city $i$ of factor $j$ in 2013. $d_{1}^{+}\left(d_{1}^{-}\right)$represents positive (negative) deviation variable of $F_{1}^{*} . d_{2}^{+}\left(d_{2}^{-}\right)$represents positive (negative) deviation variable of $F_{2}^{*}$. $d_{3}^{+}\left(d_{1}^{-}\right)$represents positive (negative) deviation variable of $F_{3}^{*} . P_{1}, P_{2}$ represent the priority level of the objective function. To control industrial wastewater emissions and industrial sulfur dioxide emissions is equally important. The importance of reducing industrial wastewater emissions industrial sulfur dioxide emissions is higher than the economic output target. Therefore, the $P_{1}$ value is 5 and $P_{2}$ value is 1 . The goal of the model is to reduce emissions of pollutants, and to make the economic output as much as possible.

\subsection{Results and Analysis of Multi Objective Programming Model}

With the aid of LINGO11.0 software, the model of multi-objective programming which is established above is calculated, and the results are obtained by the multi-objective programming model of the optimization of economic structure in Pearl River Delta. Pearl River Delta can achieve a win-win situation for the reduction of environmental pollution and economic structure optimization by using multi-objective model. According to the results in Table 2, Every 10,000 GDP industrial wastewater emissions reduce by $13.856 \%$, every 100 million industrial sulfur dioxide emissions reduce by $21.421 \%$, and regional economic growth by $4.437 \%$. The economic structure of the cities have varying degrees of change.

The model takes environmental management as a priority target to optimize. Optimization results of regional economic structure in the Pearl River Delta records in Table 3. The analysis of optimization results is as follows: Firstly, with regard to the structure of industrial, in addition to Jiangmen more reasonable, the proportion of the total industrial production value is reduced by $5 \%$ in other cities. Secondly, with regard to the structure of property right, the proportion which the urban of state-owned enterprises workers accounts for workers in urban is reduced by $5 \%$. Thirdly, with regard to the structure of urban and rural, the proportion of urban population accounts for the resident population is down by 5\% in Guangzhou, Foshan, Huizhou, Zhongshan and Jiangmen these five cities, and the proportion of urban population accounts for the resident population is increased by 5\% in Zhuhai and Dongguan. Fourthly, in technical structure, industrial enterprises new product output value of the GDP in all cities is increased by 5\%, except Zhongshan city. Fifthly, in open structure, the propotion of exports accounts for total volume of imports and exports is increased by different degrees in Zhuhai city, Foshan city, Huizhou city, Dongguan city and Zhongshan city. The open structure in Guangzhou city is more reasonable. But the propotion of exports accounts for total volume of imports and exports is higher in Shenzhen and Zhongshan. Lastly, in consumption structure, Shenzhen, Zhongshan, and Jiangmen are reduced by $5 \%$ in proportion that final consumption expenditure accounts for the local GDP. But other five cities are increased by $5 \%$.

From the optimization results, in order to achieve sustainable development of Pearl River Delta economy and environment, breaking the environmental bottleneck is the key. Not only to rely on scientific and technological progress, but also need to constantly optimize the industrial structure, ownership structure, urban and rural structure, open structure and consumption structure, economic structure and so on. The development of environment-friendly region can improve the level of environmental governance and cleaner production capacity, improve environmental quality, boost the economy, and achieve sustainable development goals in the Pearl River Delta region.

Table 2. The results of environmental objective priority model in the Pearl River delta region.

\begin{tabular}{ccc}
\hline Item & Before & After \\
Industrial wastewater (logarithm) & 20.73794 & 17.86448 \\
Industrial sulfur dioxide (logarithm) & 18.97877 & 14.91338 \\
GDP (logarithm) & 89.55826 & 93.532 \\
\hline
\end{tabular}


Table 3. Optimization of economic structure of cities.

\begin{tabular}{|c|c|c|c|c|c|c|c|}
\hline$x_{i j}$ & & $\begin{array}{l}\text { Industrial } \\
\text { structure } \\
(j=1)\end{array}$ & $\begin{array}{c}\text { Property right } \\
\text { structure }(j=2)\end{array}$ & $\begin{array}{l}\text { Urban and } \\
\text { rural } \\
\text { structure } \\
(j=3)\end{array}$ & $\begin{array}{c}\text { Technology } \\
\text { structure }(j=4)\end{array}$ & $\begin{array}{c}\text { Open } \\
\text { structure } \\
(j=5)\end{array}$ & $\begin{array}{c}\text { Consumption } \\
\text { structure }(j=6)\end{array}$ \\
\hline \multirow{3}{*}{$\begin{array}{l}\text { Guangzhou } \\
\quad(i=1)\end{array}$} & Before & 30.8 & 22.79 & 85.27 & 17.16 & 52.82 & 48.80 \\
\hline & After & 25.8 & 17.79 & 80.27 & 22.16 & 52.15 & 53.80 \\
\hline & Rate & -5 & -5 & -5 & 5 & -0.67 & 5 \\
\hline \multirow{3}{*}{$\begin{array}{l}\text { Shenzhen } \\
\quad(i=2)\end{array}$} & Before & 40.6 & 10.90 & 100 & 45.42 & 56.88 & 42.47 \\
\hline & After & 35.6 & 5.90 & 100 & 50.42 & 52.45 & 37.47 \\
\hline & Rate & -5 & -5 & 0 & 5 & -4.43 & -5 \\
\hline \multirow{3}{*}{$\begin{array}{l}\text { Zhuhai } \\
(i=3)\end{array}$} & Before & 46.7 & 13.90 & 87.85 & 52.29 & 48.96 & 40.71 \\
\hline & After & 41.7 & 8.90 & 92.85 & 57.29 & 53.96 & 45.71 \\
\hline & Rate & -5 & -5 & 5 & 5 & 5 & 5 \\
\hline \multirow{3}{*}{$\begin{array}{c}\text { Foshan } \\
(i=4)\end{array}$} & Before & 59.9 & 11.71 & 94.88 & 31.09 & 66.50 & 41.03 \\
\hline & After & 54.9 & 6.71 & 89.88 & 36.09 & 71.5 & 46.03 \\
\hline & Rate & -5 & -5 & -5 & 5 & 5 & 5 \\
\hline \multirow{3}{*}{$\begin{array}{l}\text { Huizhou } \\
(i=5)\end{array}$} & Before & 54.7 & 21.21 & 66.00 & 81.93 & 58.06 & 48.67 \\
\hline & After & 49.7 & 16.21 & 61.00 & 86.93 & 63.06 & 53.67 \\
\hline & Rate & -5 & -5 & -5 & 5 & 5 & 5 \\
\hline \multirow{3}{*}{$\begin{array}{l}\text { Dongguan } \\
\quad(i=6)\end{array}$} & Before & 44.4 & 6.33 & 88.75 & 21.39 & 59.36 & 54.65 \\
\hline & After & 39.4 & 1.33 & 93.75 & 26.39 & 64.36 & 59.65 \\
\hline & Rate & -5 & -5 & 5 & 5 & 5 & 5 \\
\hline \multirow{3}{*}{$\begin{array}{l}\text { Zhongshan } \\
\quad(i=7)\end{array}$} & Before & 53.2 & 8.65 & 88.00 & 28.53 & 74.32 & 43.20 \\
\hline & After & 48.2 & 3.65 & 83.00 & 26.25 & 78.22 & 38.20 \\
\hline & Rate & -5 & -5 & -5 & -2.28 & 3.90 & -5 \\
\hline \multirow{3}{*}{$\begin{array}{l}\text { Jiangmen } \\
\quad(i=8)\end{array}$} & Before & 48.2 & 22.7 & 64.10 & 19.45 & 70.94 & 48.82 \\
\hline & After & 47.41 & 17.7 & 59.10 & 24.45 & 67.12 & 43.82 \\
\hline & Rate & -0.79 & -5 & -5 & 5 & -3.82 & -5 \\
\hline \multirow{3}{*}{$\begin{array}{l}\text { Zhaoqing } \\
\quad(i=9)\end{array}$} & Before & 44.4 & 36.31 & 43.82 & 12.12 & 68.77 & 48.38 \\
\hline & After & 39.4 & 31.31 & 48.82 & 17.12 & 63.77 & 53.38 \\
\hline & Rate & -5 & -5 & 5 & 5 & -5 & 5 \\
\hline
\end{tabular}

\section{Policy Suggestion on Promoting the Construction of Environment Friendly Society in Pearl River Delta}

\subsection{To Materialize Government Management Functions}

The deficiency of government environmental management is the key factor of the little effect of environmental management. Regional government should guide enterprises and the public to strengthen the consciousness of environmental protection and economic development and social responsibility. Promoting sustainable development of regional economy needs government to strengthen supervision and restraint of enterprise environmental protection responsibility, to increase environmental pollution penalties, to force the relevant enterprises to change the mode of operation and production, to adopt advanced technology, to change economy grows means, to improve resource conversion capability, to reduce the generation of pollutants, and to optimize regional eco- 
nomic structure.

\subsection{To Make Reasonable and Ecological Industrial Structure}

The proportion of each industry and the balanced growth rate is the main performance of the reasonable industrial structure. Promoting industrial structure to evolve from the low level to the high level and forming a service industry as the leading industry the need to reduce the production scale of high pollution, high energy consumption and low economic output. Ecology industrial structure requires achieving cleaner production, resource recycling and emissions of pollutants as little as possible. The industrial structure will do less and less damage to the environment. Pearl River Delta region needs to scientifically plan production enterprises, to promote the mutual relationship between different enterprises, to promote the recycling of resources, and to reduce pollutant emissions from the source.

\subsection{To Make Environmental Urbanization Process}

The process of urbanization in the Pearl River Delta region must focus on the future, plan ahead, base on the ecological and green industry. According to the effective environmental regulation, innovative environmental management and advanced environmental technology, to deal with the relationship between population, economic development and environmental governance. Namely, adjustment of regional urban and rural structure should be coordinated with the regional economic and social development, ecological environment protection planning, population development and so on, regards environmental protection as a precondition, and be core with economic development.

\subsection{To Green Science and Technology}

Building environment friendly society needs to improve the green scientific and technological innovation ability, to increase R \& D investment in green scientific and technology, to accelerate the construction of green scientific and technological innovation platform, to enhance innovation capability of research center, to pay more attention to the cultivation of talents and so on.

\subsection{To Make Environmental Opening Strategy}

Pushing opening strategy to the outside world is accord with environmental protection. Optimize the structure of export products. Encourage the export enterprises to invest in high-end manufacturing, high technology industries, modern service industry, energy saving and environmental protection.

\subsection{To Green Consumption Pattern}

On the one hand, it vigorously promotes green consumption, especially enhancing the public's awareness of green consumption and environmental protection. Conduct consumers change consumption attitudes. On the other hand, it will develop green products and advocate for consumers to choose green food.

\section{References}

[1] Chinese State Council (2011) National Main Functional Area Planning.

[2] Yao, Z.Y. (2009) Analysis of Pollution Industry Shift Influencing to Chinese Environment and Economical. Ecological Economy, 25, 155-158.

[3] Grossman, G.M. and Krueger, A.B. (1994) Economic Growth and the Environment. The Quarterly Journal of Economics, 110, 353-377. http://dx.doi.org/10.2307/2118443

[4] Bruvoll, A. and Medin, H. (2003) Factors Behind the Environmental Kuznets Curve. A Decomposition of the Changes in Air Pollution. Environmental and Resource Economics, 24, 27-48. http://dx.doi.org/10.1023/A:1022881928158

[5] Stern, D.I. (2002) Explaining Changes in Global Sulfur Emissions: An Econometric Decomposition Approach. Ecological Economics, 42, 201-220. http://dx.doi.org/10.1016/S0921-8009(02)00050-2

[6] Shandra, J.M., Shor, E. and London, B. (2008) Structural Adjustment and Organic Water Pollution a Cross-National Analysis. Organization \& Environment, 21, 38-55. http://dx.doi.org/10.1177/1086026608314759

[7] Jalil, A. and Feridun, M. (2011) The Impact of Growth, Energy and Financial Development on the Environment in 
China: A Cointegration Analysis. Energy Economics, 33, 284-291. http://dx.doi.org/10.1016/j.eneco.2010.10.003

[8] Liu, X.S. and Li, G. (2005) Individual Difference Scaling Analysis on Relations of Industry Structure and Environmental Effect-Concurrently Analysis on Harbin Optimized Promotion of Industry Structure. Economy and Management, 20, 58-60.

[9] Peng, S.J. and Bao, Q. (2006) Economic Growth and Environmental Pollution: An Empirical Test for the Environmental Kuznets Curve Hypothesis in China. Research on Financial and Economic Issues, 28, 3-17.

[10] Su, Y.Z. (2010) Energy Saving, Emission Reduction, Optimization of Industrial Structure and Transformation of Economic Development Mode in Zhenjiang. M.Ec. Thesis, Jiangsu University, Zhenjiang.

[11] Zhang, P.D., Zhu, S. and Ge, Y.L. (2012) The Role of Economic Structure in the Pollution Control-Empirical Study on Chinese Statistics in 1985-2009. Journal of Lanzhou Commercial College, 28, 59-64.

[12] Liu, C. (2014) An Empirical Study on the Environmental Effects of Industrial Structure Adjustment in Anhui Province. Journal of Suzhou University, 29, 19-23.

[13] Yuan, Y.J. and Xie, R.H. (2014) Research on the Effect of Environmental Regulation to Industrial Restructuring-Empirical Test Based on Provincial Panel Data of China. China Industrial Economics, 32, 57-69.

[14] Guangdong Provincial Environmental Protection Department (2013) Guangdong Provincial Environmental Bulletin. http://www.gdep.gov.cn/hjjce/gb/2013hjgb/201406/t20140605 170408.html 